\title{
Non-Arteritic Anterior Ischemic Optic Neuropathy (NAION)-A Brief Review
}

\author{
Mukesh Patil, Anita Ganger*, Rohit Saxena \\ Neuro-Ophthalmic Services, Dr. Rajendra Prasad Centre for Ophthalmic Sciences, All India Institute of Medical \\ Sciences, New Delhi, India \\ Email: *anitaganger@gmail.com
}

Received 26 April 2016; accepted 9 August 2016; published 12 August 2016

Copyright @ 2016 by authors and Scientific Research Publishing Inc.

This work is licensed under the Creative Commons Attribution International License (CC BY).

http://creativecommons.org/licenses/by/4.0/

c) (i) Open Access

\begin{abstract}
Ischemic optic neuropathies could be a result of inflammatory and non inflammatory small vessel disease and have been classified as arteritic and non-arteritic anterior ischemic optic neuropathy respectively. This review has been intended to elucidate the epidemiology, etiology, pathogenesis, clinical picture and management of NAION and the literature search was completed using the published data in Pubmed, Medline, and Ovid over the last five decades.
\end{abstract}

\section{Keywords}

Ischemia, Optic Neuropathy, Arteritic, Non-Arteritic

\section{Introduction}

Ischemic optic neuropathies are of two types-anterior and posterior, based on location of ischemic damage. Anterior ischemic optic neuropathy (AION) presents with visible disc edema due to ischemic damage to anterior portion of optic nerve supplied by posterior ciliary arteries (PCA). AION is the most common cause of acute optic nerve ischemia related vision loss in adults and second most common cause of optic nerve related permanent vision loss in adults after glaucoma [1]. AION is divided into arteritic and non-arteritic types. Arteritic anterior ischemic optic neuropathy (AAION) is secondary to inflammatory small vessel disease, i.e., vasculitis, whereas non-arteritic anterior ischemic optic neuropathy (NAION) is secondary to non inflammatory small vessel disease [2]. Chronic inflammation in arteritic anterior ischemic optic neuropathy causes inflammatory thickening, thrombosis and occlusion of short posterior ciliary arteries supplying optic nerve head leading to ischemia of laminar and retro laminar portion of optic nerve head while in non-arteritic anterior ischemic optic neuropathy, non inflammatory ischemia of short posterior ciliary arteries due to various reasons leads to ischemic damage to

"Corresponding author.

How to cite this paper: Patil, M., Ganger, A. and Saxena, R. (2016) Non-Arteritic Anterior Ischemic Optic Neuropathy (NAION)-A Brief Review. Open Journal of Ophthalmology, 6, 158-163. http://dx.doi.org/10.4236/ojoph.2016.63022 
retro laminar portion of optic nerve head [2].

The search of published literature for this review article had been completed using Ovid, Medline, Embase, Pubmed over the last 5 decades along with the checking of cross references also. English language articles with full text access were included and electronic literature search was performed using ischemia, optic neuropathy, arteritic, non-arteritic as key words. While reviewing the literature, parameters evaluated in studies were epidemiological data, etiological factors, clinical features and management modalities.

\section{Epidemiology}

NAION is the most common form, constitutes $95 \%$ of AION and is the most common cause of acute optic neuropathy over the age of 50 years [3]. Only few studies have reported the incidence and prevalence of NAION in past literature. The Beijing eye study estimated prevalence of 1 in 45,000 in Chinese population with age $>40$ years [4], while study done in Caucasians estimated annual incidence of $2.3-10.2$ per 100,000 population with age $>50$ years [3] [5]. However, annual prevalence of NAION was reported as $0.30 \%$ [6] and incidence was found to be as high as 82 cases per 100,000 [7] in large Medicare database study. NAION occurs more frequently in white population than black or Hispanic individuals. Inter-ethnic differences in frequency of NAION may be attributed to the different size of optic disc which occurs predominately in small optic nerve head. The smallest sized discs are found in Caucasians, medium sized discs in Asians and largest sized discs in AfroAmericans [4].

NAION occurs with equal frequency in males and females. Mean age reported was 66 years in IONDT [3] (ischemic optic nerve decompression trial), while in most other studies documented age range is 57 - 65 years [3] [8].

\section{Etiology}

NAION is most often idiopathic, though many systemic as well as ocular risk factors are identified. Among systemic factors nocturnal hypotension, hypertension, diabetes mellitus, hyperlipidemia, and smoking are associated, whereas among ocular risk factors crowding of optic nerve head is the important one.

In IONDT, $47 \%$ of NAION patients had hypertension, $24 \%$ had diabetes and $60 \%$ had at least one vasculopathic risk factor [8]. These figures are similar to other studies in which systemic hypertension was reported in $39 \%-49 \%$ of patients and diabetes was reported in 5\% - 25.3\%. In several studies, after comparing systemic hypertension with normal data, statistically significant increase in prevalence was found in 45 - 65 year age [9] group while Hyreh et al. [10] found similar prevalence in all the age groups. Diabetes was associated with increased prevalence in all age groups in most of the studies.

Case control study for NAION done by Jacobson et al. [11] found no association of hypercholesterolemia and smoking with NAION. While case control study done by Salomon et al. [12] documented hypercholesterolemia to be a significant factor. Few more studies concluded association of smoking with NAION on basis of higher prevalence of NAION in smokers at younger age group as compared to nonsmokers.

Clinical significance between hyper homo cystenemia and NAION is uncertain. Large scale study was done by Salomon et al. [12] to document correlation between prothrombic risk factors like lupus anticoagulants, anti cardiolipin antibodies, prothrombotic polymorphisms (factor V Leiden), and deficiencies of protein C and S and antithrombin III and NAION however, no significant correlation was found with any of these.

Other risk factors include obstructive sleep apnea, medications like interferon alpha, sildenafil and amiodarone.

\section{Pathogenesis}

NAION is caused by circulatory insufficiency in small vessels of optic nerve head. After years of studies and recent advances in investigational modalities, exact mechanism and location of vasculopathy is still unproven. Ischemia may result from localized arteriosclerosis with or without thrombosis, embolization from a remote source, generalized hypoperfusion, vasospasm, failure of autoregulation, or a combination of these processes. Autoregulatory mechanisms may be reduced by arteriosclerosis, vasospasm, or medications.

Histopathological studies showed infarction predominantly involving retro laminar part of optic nerve head that is supplied by para optic branches of short posterior ciliary arteries (SPCA), while involvement of choroidal 
blood vessels which supply laminar and prelaminar part of optic nerve head is less likely [2].

Electron microscopic studies have shown that optic nerve head is supplied from anastomotic circle derived from SPCA, with distinct upper and lower halves consistent with altitudinal defects seen in NAION [2].

Crowded optic nerve head with absent or $\leq 0.2$ cupping acts as a risk factor to NAION. Possible mechanism includes mechanical obstruction to axoplasmic flow with axonal swelling particularly at the cribriform plate. [1] [13].

Interferon alpha may cause systemic hypotension or immune complex deposition within the optic disc circulation, while Sildenafil, a phospho diesterase 5 inhibitor, commonly used for erectile dysfunction may produce systemic hypotension and amiodarone, an anti-arrhythmic drug impairs axoplasmic flow and causes chronic metabolic optic disc dysfunction and swelling [1] [14].

\section{Clinical Features}

NAION usually presents as sudden, painless uniocular loss of vision over hours to days. Often presents as visual field defects especially inferior. Pain on ocular movements is rare. A relative afferent pupillary defect is always present, if condition is unilateral and there is no optic nerve or retinal pathology in the fellow eye. Visual acuity varies from 20/40 to no perception of light. NAION usually presents with less severe visual loss than AAION. In the IONDT, 49\% had initial visual acuity of at least 20/64 and 66\% had better than 20/200 [8].

Optic disc may have diffuse or segmental, hyperemic or pallid edema but pallor occurs less frequently than in the arteritic form. Peripapillary flame shaped hemorrhages are common while soft and hard exudates are rare. In IONDT, 72\% had hemorrhages while only 7\% had exudates [8]. In terms of visual field loss, typical NAION shows altitudinal loss, usually inferior in $50 \%-80 \%$ of cases. Pattern loss related to axonal damage may also be present.

\section{Investigations}

\subsection{Fundus Fluorescein Angiography}

In contrast to AAION which shows consistent impaired filling of choroid and optic disc in peripapillary area as well as diffusely also, NAION is associated with impaired filling of prelaminar optic disc with normal choroidal and retinal filling [15] [16].

\subsection{ICG Angiography}

ICG studies of the choroidal flow show delayed filling in AAION but not in NAION. These findings are suggestive of vascular impairment at level of paraoptic branches of SPCA rather than proximal branches which would delay both choroidal and optic nerve head flow [17]-[19].

\subsection{Colour Doppler}

Colour doppler studies have not localized the location of impaired flow and results were criticized [20].

\subsection{Laser Doppler Flow}

Laser Doppler flow studies have also not conclusively localized the location of impaired flow [21].

\section{Prognosis}

As per IONDT study, the visual prognosis in affected eye documented was 35\% eyes had visual acuity better than 20/64, 36\% had worse than 20/200 at 6 months and 52\% had visual acuity worse than 20/200 after 6 months. Risk of recurrence documented in affected eye was less than $5 \%$ and risk of involvement of fellow eye reported was $14.7 \%$ over 5 years [22].

\section{Management}

Treatment of NAION is still controversial and there is no effective and proven treatment for NAION established 
yet.

\subsection{Medical Treatment}

Aspirin and antiplatelets: Role of aspirin in decreasing severity and incidence in fellow eye is controversial. No benefit in visual outcome was found in retrospective study using aspirin. No studies of clopidogrel and dipyridamole use in treatment of NAION reported yet [23].

Steroids: Rationale of steroids use in NAION is to decrease optic disc edema, prevent further axonal damage and improve blood flow in acute cases [24]. Few studies [25] [26] in literature concluded role of oral steroids in improvement of visual acuity and fields but results were not accepted due to non-randomization, small sample size, selection bias. No studies have documented role of intravenous steroids.

Others: Treatments attempted include vasopressor agents (nor epinephrine), vasodilators, anticoagulants, diphenyl hydantoin, and heparin-induced low-density lipoprotein/fibrinogen precipitation. None of drug had shown effectiveness.

\subsection{Surgical Treatment}

Intravitreal triamcinolone acetonide: Few small case series reported improvement in visual acuity after 4mg intravitreal injection but studies with large sample size and long follow up needed. Also rise of intra ocular pressure and worsening of optic neuropathy is of great concern [27] [28].

Intravitreal bevacizumab: Though small case series reported no improvement or slight improvement in visual acuity after $1.25 \mathrm{mg} / 0.1 \mathrm{ml}$ of injection. But not accepted as treatment modality [29] [30].

Transvitreal optic neurotomy: In small study with 16 subjects, 8 patients were randomized to procedure which involved pars plana vitrectomy, posterior vitreous detachment induction and stab incision at the nasal margin of the optic disc, with the purpose of opening the scleral canal and relieving compression of an edematous optic nerve head. Intervention showed moderate visual improvement but because of experimental nature, results should be interpreted with caution [31].

Optic nerve decompression surgery: The rationale was to relieve compartment syndrome and to improve blood flow and axonal flow. But the IONDT found that surgery was not just ineffective but might be harmful [32].

\subsection{Secondary Prevention (Prophylaxis to Prevent Fellow Eye Involvement)}

Aspirin: Studies in literature do not provide sufficient evidence to support aspirin therapy for prevention [33][35] Retinal laser photocoagulation: To create axonal drop out and optic atrophy in eyes with crowded optic disc axons. Therapy is not accepted, as laser photocoagulation itself leads to visual field defects [36].

Correction of modifiable risk factors: Hypertension, diabetes, sleep apnea, hyperlipidemia, anemia can be controlled to prevent fellow eye involvement [37] [38].

\section{Conclusion}

Non-ischemic arteritic optic neuropathy was found to be the most common form, which constitutes $95 \%$ of AION and is the most common cause of acute optic neuropathy over the age of 50 years. Though no proper guidelines have still been established for the prompt management of NAION, but investigative modalities such as colour Doppler, fundus fluorescein angiography, and ICG angiography may assist in establishing the early diagnosis and proper management of such cases.

\section{References}

[1] Miller, N.R. and Arnold, A.C. (2015) Current Concepts in the Diagnosis, Pathogenesis and Management of Nonarteritic Anterior Ischaemic Optic Neuropathy. Eye (Lond), 29, 65-79. http://dx.doi.org/10.1038/eye.2014.144

[2] Arnold, A.C. (2003) Pathogenesis of Nonarteritic Anterior Ischemic Optic Neuropathy. Journal of Neuroophthalmology, 23, 157-163. http://dx.doi.org/10.1097/00041327-200306000-00012

[3] Guyer, D.R., Miller, N.R., Auer, C.L. and Fine, S.L. (1985) The Risk of Cerebrovascular and Cardiovascular Disease in Patients with Anterior Ischemic Optic Neuropathy. Archives of Ophthalmology, 103, 1136-1142. http://dx.doi.org/10.1001/archopht.1985.01050080048018 
[4] Wang, Y., Xu, L. and Jonas, J.B. (2007) Frequency of Non-Arteritic Anterior Ischaemic Optic Neuropathy in Adult Chinese: The Beijing Eye Study. British Journal of Ophthalmology, 91, 401. http://dx.doi.org/10.1136/bjo.2006.103788

[5] Johnson, L.N. and Arnold, A.C. (1994) Incidence of Nonarteritic and Arteritic Anterior Ischemic Optic Neuropathy: Population Based Study in the State of Missouri and Los Angeles County, California. Journal of Neuroophthalmology, 14, 38-44. http://dx.doi.org/10.1097/00041327-199403000-00011

[6] Gordon, L.K., Yu, F., Coleman, A.L., et al. (2003) Medicare Database Analysis of Prevalence and Risk Factors for Ischemic Optic Neuropathy. Ophthalmology, 110, 238.

[7] Lee, M.S., Grossman, D., Arnold, A.C. and Sloan, F.A. (2011) Incidence of Nonarteritic Anterior Ischemic Optic Neuropathy: Increased Risk among Diabetic Patients. Ophthalmology, 118, 959-963.

http://dx.doi.org/10.1016/j.ophtha.2011.01.054

[8] Ischemic Optic Neuropathy Decompression Trial Research Group (1996) Characteristics of Patients with Nonarteritic Anterior Ischemic Optic Neuropathy Eligible for the Ischemic Optic Neuropathy Decompression Trial. Archives of Ophthalmology, 114, 1366-1374. http://dx.doi.org/10.1001/archopht.1996.01100140566007

[9] Repka, M.X., Savino, P.J., Schatz, N.J. and Sergott, R.C. (1983) Clinical Profile and Long-Term Implications of Anterior Ischemic Optic Neuropathy. American Journal of Ophthalmology, 96, 478-483. http://dx.doi.org/10.1016/S0002-9394(14)77911-5

[10] Hayreh, S.S., Joos, K.M., Podhajsky, P.A. and Long, C.R. (1994) Systemic Diseases Associated with Nonarteritic Anterior Ischemic Optic Neuropathy. American Journal of Ophthalmology, 118, 766-780. http://dx.doi.org/10.1016/S0002-9394(14)72557-7

[11] Jacobson, D.M., Vierkant, R.A. and Belongia, E.A. (1997) Nonarteritic Anterior Ischemic Optic Neuropathy. A CaseControl Study of Potential Risk Factors. Archives of Ophthalmology, 115, 1403-1407. http://dx.doi.org/10.1001/archopht.1997.01100160573008

[12] Salomon, O., Huna-Baron, R., Kurtz, S., et al. (1999) Analysis of Prothrombotic and Vascular Risk Factors in Patients with Nonarteritic Anterior Ischemic Optic Neuropathy. Ophthalmology, 106, 739-742. http://dx.doi.org/10.1016/S0161-6420(99)90159-8

[13] McLeod, D., Marshall, J. and Kohner, E.M. (1980) Role of Axoplasmic Transport in the Pathophysiology of Ischaemic Disc Swelling. British Journal of Ophthalmology, 64, 247-261. http://dx.doi.org/10.1136/bjo.64.4.247

[14] Pomeranz, H.D. and Bhavsar, A.R. (2005) Nonarteritic Ischemic Optic Neuropathy Developing Soon after Use of Sildenafil (Viagra): A Report of Seven New Cases. Journal of Neuroophthalmology, 25, 9-13. http://dx.doi.org/10.1097/00041327-200503000-00003

[15] Eagling, E.M., Sanders, M.D. and Miller, S.J.H. (1974) Ischaemic Papillopathy: Clinical and Fluorescein Angiographic Review of Forty Cases. British Journal of Ophthalmology, 58, 990-1008. http://dx.doi.org/10.1136/bjo.58.12.990

[16] Hayreh, S.S. (1990) Anterior Ischaemic Optic Neuropathy. Differentiation of Arteritic from Non-Arteritic Type and Its Management. Eye, 4, 25-41. http://dx.doi.org/10.1038/eye.1990.4

[17] Sadun, F., Pece, A. and Brancato, R. (1998) Fluorescein and Indocyanine Green Angiography in Arteritic Anterior Ischaemic Optic Neuropathy. British Journal of Ophthalmology, 82, 1344-1345. http://dx.doi.org/10.1136/bjo.82.11.1339h

[18] Meadows, M., Slavin, M., Beer, P.M. and Krohel, G.B. (1998) Indocyanine Green Angiography of Anterior Ischemic Optic Neuropathy and Giant Cell Arteritis. NANOS Annual Meeting.

[19] Oto, S., Yilmaz, G., Cakmakci, S. and Aydin, P. (2002) Indocyanine Green and Fluorescein Angiography in Nonarteritic Anterior Ischemic Optic Neuropathy. Retina, 22, 187-191.

[20] Petrig, B.L., Riva, C.E. and Hayreh, S.S. (1999) Laser Doppler Flowmetry and Optic Nerve Head Blood Flow. American Journal of Ophthalmology, 127, 413-425. http://dx.doi.org/10.1016/S0002-9394(98)00437-1

[21] Leiba, H., Rachmiel, R., Harris, A., Kagemann, L., Pollack, A. and Zalish, M. (2000) Optic Nerve Head Blood Flow Measurements in Non-Arteritic Anterior Ischemic Optic Neuropathy. Eye, 14, 828-833. http://dx.doi.org/10.1038/eye.2000.231

[22] Newman, N.J., Scherer, R., Langenberg, P., et al. (2002) The Fellow Eye in NAION: Report from the Ischemic Optic Neuropathy Decompression Trial Follow-Up Study. American Journal of Ophthalmology, 134, 317-328. http://dx.doi.org/10.1016/S0002-9394(02)01639-2

[23] Botelho, P.J., Johnson, L.N. and Arnold, A.C. (1996) The Effect of Aspirin on the Visual Outcome of Nonarteritic Anterior Ischemic Optic Neuropathy. American Journal of Ophthalmology, 121, 450-451. http://dx.doi.org/10.1016/S0002-9394(14)70448-9

[24] Foulds, W.S. (1970) Visual Disturbances in Systemic Disorders: Optic Neuropathy and Systemic Disease. Transactions of the Ophthalmological Societies of the United Kingdom, 89, 125-146. 
[25] Hayreh, S.S. and Zimmerman, M.B. (2008) Non-Arteritic Anterior Ischemic Optic Neuropathy: Role of Systemic Corticosteroid Therapy. Graefe's Archive for Clinical and Experimental Ophthalmology, 246, 1029-1046. http://dx.doi.org/10.1007/s00417-008-0805-8

[26] Hayreh, S.S. (1974) Anterior Ischemic Optic Neuropathy. III. Treatment, Prophylaxis and Differential Diagnosis. British Journal of Ophthalmology, 58, 981-989. http://dx.doi.org/10.1136/bjo.58.12.981

[27] Kaderli, B., Avci, R., Yucel, A., et al. (2007) Intravitreal Triamcinolone Improves Recovery of Visual Acuity in Nonarteritic Anterior Ischemic Optic Neuropathy. Journal of Neuro-Ophthalmology, 27, 164-168. http://dx.doi.org/10.1097/WNO.0b013e31814a5a9a

[28] Yaman, A., Selver, O.B., Saatci, A.O. and Soylev, M.F. (2008) Intravitreal Triamcinolone Acetonide Injection for Acute Nonarteritic Anterior Ischemic Optic Neuropathy. Clinical and Experimental Optometry, 91, 561-564. http://dx.doi.org/10.1111/j.1444-0938.2008.00287.x

[29] Prescott, C.R., Sklar, C.A., Lesser, R.L. and Adelman, R.A. (2012) Is Intravitreal Bevacizumab an Effective Treatment Option for Nonarteritic Anterior Ischemic Optic Neuropathy? Journal of Neuro-Ophthalmology, 32, 51-53. http://dx.doi.org/10.1097/WNO.0b013e318240596e

[30] Bennett, J.L., Thomas, S., Olson, J.L. and Mandava, N. (2007) Treatment of Nonarteritic Anterior Ischemic Optic Neuropathy with Intravitreal Bevacizumab. Journal of Neuro-Ophthalmology, 27, 238-240. http://dx.doi.org/10.1097/WNO.0b013e31814b273d

[31] Soheilian, M., Koochek, A., Yazdani, S. and Peyman, G.A. (2003) Transvitreal Optic Neurotomy for Nonarteritic Anterior Ischemic Optic Neuropathy. Retina, 23, 692-697. http://dx.doi.org/10.1097/00006982-200310000-00015

[32] Ischemic Optic Neuropathy Decompression Trial Research Group (1995) Optic Nerve Decompression Surgery for Nonarteritic Anterior Ischemic Optic Neuropathy (NAION) Is Not Effective and May Be Harmful. JAMA, 273, 625632. http://dx.doi.org/10.1001/jama.1995.03520320035038

[33] Beck, R.W., Hayreh, S.S., Podhajsky, P.A., Tan, E.-S. and Moke, P.S. (1997) Aspirin Therapy in Nonarteritic Anterior Ischemic Optic Neuropathy. American Journal of Ophthalmology, 123, 212-217. http://dx.doi.org/10.1016/S0002-9394(14)71038-4

[34] Kupersmith, M.J., Frohman, L., Sanderson, M., et al. (1997) Aspirin Reduces the Incidence of Second Eye NAION: A Retrospective Study. Journal of Neuro-Ophthalmology, 17, 250-253. http://dx.doi.org/10.1097/00041327-199712000-00007

[35] Salomon, O., Huna-Baron, R., Steinberg, D.M., Kurtz, S. and Seligsohn, U. (1999) Role of Aspirin in Reducing the Frequency of Second Eye Involvement in Patients with Non-Arteritic Anterior Ischaemic Optic Neuropathy. Eye, 13, 357-359. http://dx.doi.org/10.1038/eye.1999.90

[36] Burde, R.M. (1993) Optic Disc Risk Factors for Nonarteritic Anterior Ischemic Optic Neuropathy. American Journal of Ophthalmology, 116, 759-764. http://dx.doi.org/10.1016/S0002-9394(14)73478-6

[37] Archer, E.L. and Pepin, S. (2013) Obstructive Sleep Apnea and Nonarteritic Anterior Ischemic Optic Neuropathy: Evidence for an Association. Journal of Clinical Sleep Medicine, 9, 613-618. http://dx.doi.org/10.5664/jcsm.2766

[38] Deramo, V.A., Sergott, R.C., Augsburger, J.J., et al. (2003) Ischemic Optic Neuropathy as the First Manifestation of Elevated Cholesterol in Young Patients. Ophthalmology, 110, 1041-1046. http://dx.doi.org/10.1016/S0161-6420(03)00079-4 


\section{Submit or recommend next manuscript to SCIRP and we will provide best service for you:}

Accepting pre-submission inquiries through Email, Facebook, LinkedIn, Twitter, etc.

A wide selection of journals (inclusive of 9 subjects, more than 200 journals)

Providing 24-hour high-quality service

User-friendly online submission system

Fair and swift peer-review system

Efficient typesetting and proofreading procedure

Display of the result of downloads and visits, as well as the number of cited articles

Maximum dissemination of your research work

Submit your manuscript at: http://papersubmission.scirp.org/ 